\title{
A field-based investigation of behavioural interactions between invasive green crab (Carcinus maenas), rock crab (Cancer irroratus), and American lobster (Homarus americanus) in southern Newfoundland
}

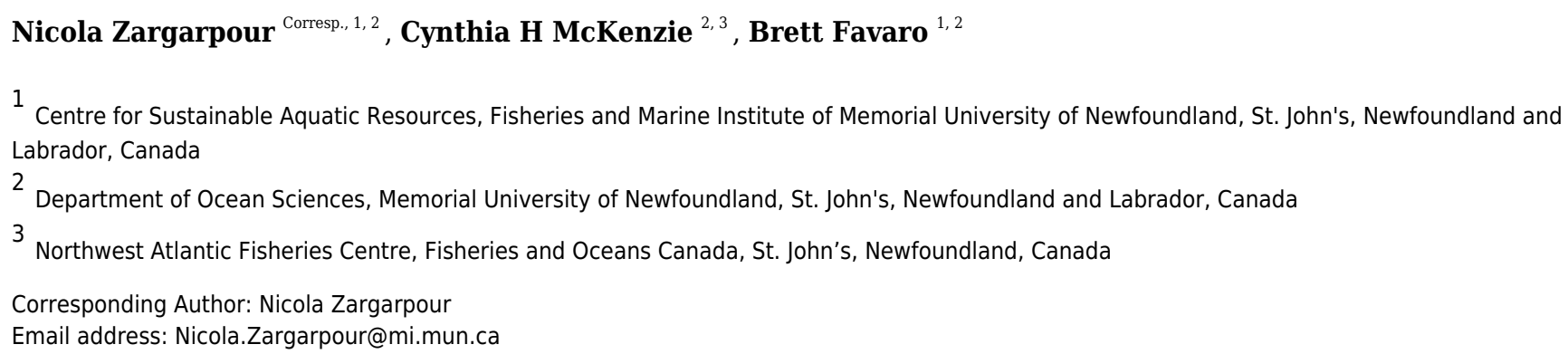

Marine species invasions pose a global threat to native biodiversity and commercial fisheries. The European green crab (Carcinus maenas) is one of the most successful marine invaders worldwide and has, in the last decade, invaded the southern and western coastal waters of the island of Newfoundland, Newfoundland and Labrador (NL), Canada. Impacts of green crab on the American lobster (Homarus americanus), which are native to Newfoundland, are not well understood, particularly for interactions around deployed fishing gear. Declines in lobster catch rates in invaded systems (i.e., Placentia Bay, NL), have prompted concerns among lobster fishers that green crab are interfering with lobster catch. Here, we conducted a field experiment in a recently-invaded bay (2013) in which we deployed lobster traps pre-stocked with green crab, native rock crab (Cancer irroratus) (a procedural control), or empty (control). We compared catch per unit effort across each category, and used underwater cameras to directly observe trap performance in situ. In addition, we used SCUBA surveys to determine the correlation between ambient density of lobster and green crab in the ecosystem and the catch processes of lobster in traps. We found: 1) Regardless of the species of crab stocked, crab presence reduced the total number of lobster that attempted to enter the trap, and also reduced entry success rate, 2) lobster consumed green crab, rock crab and other lobster inside traps and 3) there was a positive association between lobster catch and ambient lobster density. Our results suggest that while there was a relationship between in-trap crab density and trap catch rates, it was not linked to the non-native/native status of the crab species. 
1 A field-based investigation of behavioural interactions between invasive green crab

2 (Carcinus maenas), rock crab (Cancer irroratus), and American lobster (Homarus

3 americanus) in southern Newfoundland

4 Nicci Zargarpour ${ }^{1,2}$, Cynthia H. McKenzie ${ }^{2,3}$, Brett Favaro ${ }^{1,2}$

$5 \quad{ }^{1}$ Centre for Sustainable Aquatic Resources, Fisheries and Marine Institute of Memorial

6 University of Newfoundland, St. John's, Newfoundland, Canada

$7 \quad{ }^{2}$ Department of Ocean Sciences, Memorial University of Newfoundland, St. John's,

8 Newfoundland and Labrador, Canada

$9{ }^{3}$ Northwest Atlantic Fisheries Centre, Fisheries and Oceans Canada, St. John's, Newfoundland,

10 Canada

12 Corresponding Author:

13 Nicci Zargarpour

14 Email address: 9nz7@queensu.ca 
22 ABSTRACT

23 Marine species invasions pose a global threat to native biodiversity and commercial fisheries.

24 The European green crab (Carcinus maenas) is one of the most successful marine invaders

25 worldwide and has, in the last decade, invaded the southern and western coastal waters of the

26 island of Newfoundland, Newfoundland and Labrador (NL), Canada. Impacts of green crab on

27 the American lobster (Homarus americanus), which are native to Newfoundland, are not well

28 understood, particularly for interactions around deployed fishing gear. Declines in lobster catch

29 rates in invaded systems (i.e., Placentia Bay, NL), have prompted concerns among lobster fishers

30 that green crab are interfering with lobster catch. Here, we conducted a field experiment in a

31 recently-invaded bay (2013) in which we deployed lobster traps pre-stocked with green crab,

32 native rock crab (Cancer irroratus) (a procedural control), or empty (control). We compared

33 catch per unit effort across each category, and used underwater cameras to directly observe trap

34 performance in situ. In addition, we used SCUBA surveys to determine the correlation between

35 ambient density of lobster and green crab in the ecosystem and the catch processes of lobster in

36 traps. We found: 1) Regardless of the species of crab stocked, crab presence reduced the total

37 number of lobster that attempted to enter the trap, and also reduced entry success rate, 2) lobster

38 consumed green crab, rock crab and other lobster inside traps and 3) there was a positive

39 association between lobster catch and ambient lobster density. Our results suggest that while

40 there was a relationship between in-trap crab density and trap catch rates, it was not linked to the

41 non-native/native status of the crab species. 
44

45

46

47

48

49

50

51

52

53

54

\section{Introduction}

Species invasions within marine ecosystems can drive ecological change, which can have wide-reaching implications for fisheries (Albins and Hixon., 2008; Green et al., 2012). The conservation and management of marine resources requires we understand the impact an invasive species can have on ecosystem dynamics. The European green crab (Carcinus maenas) is a crustacean species native to North African and European waters (Williams, 1984). Owing to their success in invading new ecosystems and the severity of their impacts once invasion occurs, the European green crab is ranked among the 100 'worst alien invasive species' in the world (Lowe et al., 2000).

Green crab were first detected outside their native range in the early 19th century in the north-eastern United States, likely transported via ballast or hull fouling (Behrens Yamada, 2001). During the years that followed, green crab populations moved northward, reaching the Canadian border in 1951, establishing in the Bay of Fundy and south-eastern Nova Scotia by the 1960s, and subsequently in north-eastern Nova Scotia by the 1990s (Carlton and Cohen, 2003). The first observations of green crab in the province of NL occurred in 2007. Demographic data and surveys suggest that populations have existed for longer, and may have been introduced in the early 2000s (Blakeslee et al., 2010). They have since become established across the south and west coasts of the island of Newfoundland (Best et al., 2017).

The ecological impacts of green crab invasions can be severe. On the east coast of North America, the species has contributed to the degradation of eelgrass beds (Garbary et al., 2014;

Matheson et al., 2016), declines of soft-shelled clam (Mya arenaria) populations (Tan and Beal, 2015), as well as having negative impacts on oyster (Crassostrea virginica) and mussel (Mytilus 
66

67

68

69

70

71

72

73

74

75

76

77

78

79

80

81

82

83

84

85

86

87

edulis) beds (DeGraaf and Tyrrell, 2004; Miron et al., 2005). The crabs' ability to alter

ecosystem dynamics make them a serious threat to many crustacean and bivalve fisheries (DFO, 2011).

There is concern that European green crab may have negatively impacted lobster

populations through predation, competition and habitat modification in Placentia Bay, NL where they were first detected (DFO, 2016); and that their continued spread could be detrimental to other areas, particularly the south coast of Newfoundland, where lobster fishing is commercially important. Since 1992, lobster landings in Placentia Bay have severely dropped from 427 t to 20 $\mathrm{t}$ in 2017 , representing an $80 \%$ decline in an area that was once the most productive lobster fishing area in the region (DFO, 2018). While the decline began before the onset of a green crab invasion, the presence of the species may complicate lobster recovery in the region. In 2018 during a targeted mitigation in five locations in Placentia Bay 90 tons of green crab were removed and destroyed (pers. comm., K. Best, 2018). The ongoing expansion of green crab into productive lobster fishing grounds has raised concern that additional damage to the lobster stock may occur (DFO, 2016).

Green crab can impact lobster populations through a variety of mechanisms. For example, Rossong et al., 2011, found juvenile lobster (25-51 mm carapace length) in aquariums that contained green crab favoured shelter use over feeding. This behavioural impact, which was absent in aquariums without green crab, resulted in reduced energy intake by the lobster. Other laboratory studies have indicated that adult green crab (53-76 mm carapace width) predate on juvenile lobster (28-57 mm carapace length) (Rossong et al., 2006), and outcompete sub-adult lobster (55-70 mm carapace length) for a limited food source (Williams et al., 2006). However, 
88 we are unaware of any studies to date examining how these species interact outside the

89 laboratory environment.

90 It is not clear whether observed declines in lobster catch rates in invaded ecosystems

91 were due to a reduction in lobster abundance or because green crab were interfering with the

92 capture process itself (or a combination of these factors). In this study, we conducted a series of

93 field experiments to determine whether green crab had a direct impact on the ability of

94

95

96

97 commercial lobster traps to catch lobster, and to identify the mechanism by which this impact may be occurring. We employed three pre-stocking conditions (traps with green crab, traps with native crab, and traps with no pre-stocked crab) to assess the impact that green crab had on lobster catch rates. Further, we used a custom-built underwater video camera (described in Bergshoeff et al., 2017) to directly observe traps during deployments and assess the behaviour of lobster in relation to both species of crabs. Finally, we conducted SCUBA surveys around the deployed camera traps to assess the extent to which our observations were mediated by the densities of lobster, green crab, and native rock crab in the vicinity of deployed gear.

We tested four non-exclusive questions. First, do traps pre-stocked with green crab catch fewer lobster per deployment than unstocked traps? Second, if green crab do reduce lobster catch rates, do they do so by depleting bait, by physically preventing lobster entry into traps (i.e. blocking entrances), or by inducing lobster to exit the traps? Third, does the density of green crab in the vicinity of deployed traps reduce lobster catch rates? Finally, are these effects specific to green crab, or do they occur with native rock crab as well?

Peer) reviewing PDF | (2019:01:34310:2:0:NEW 13 Dec 2019) 


\section{Materials \& Methods}

\subsection{Specifications of camera apparatus}

To record underwater video of lobster traps fishing in situ we designed and assembled a camera system capable of recording full high-definition videos for 13 continuous hours at high resolution (1080p) (see Bergshoeff et al., 2017). We mounted the camera housing to a wooden

117 frame constructed around standard commercial single-parlour wire-mesh (3.8 $\mathrm{cm}$ mesh size) lobster traps capable of catching all types of crustaceans. We secured the housing to this frame and oriented the camera $58 \mathrm{~cm}$ above the trap pointing downward, giving a top-down field of view (FOV) of approximately $105 \mathrm{~cm}$ by $170 \mathrm{~cm}$ underwater. Using this setup we were able to observe lobster entering, exiting, inside the trap, as well as those around the trap for 13 continuous hours. We attached a Data Storage Tag (DST) to record the depth at which each trap was deployed, but due to a technological malfunction these data were not recoverable. We

124 deployed the traps at depths shallow enough for ambient light to illuminate the pot during the day, therefore we did not use external lights. Traps were deployed within depths reflective of where commercial lobster traps are set (i.e. $<20 \mathrm{~m}$ at low tide; DFO, 2016).

We conducted field work in nearshore lobster fishing areas around Little Harbour East and Little Bay East, Fortune Bay on the southern coast of Newfoundland (Figure 1) for five weeks between July-September 2016, directly following the closure of the two-month lobster 
131 fishery in Lobster Fishing Area (LFA) 11 (DFO, 2016). This allowed us to carry out our field 132 experiments and SCUBA surveys without interfering with local fishing operations or having to

133

134

135 work around other fishing gears and vessels. We selected specific sites within the region based on advice from fishers, scientists (K. Matheson, Aquatic Science Biologist, Fisheries and Oceans Canada (DFO), personal communication, June 2016), and local members of the community.

We deployed all traps at depths ranging from 3 to $19 \mathrm{~m}$ (mean \pm 1 S.D. $=9.52 \pm 4.27 \mathrm{~m}$ as measured at low tide), using a $4.2 \mathrm{~m}$ rigid-hull inflatable boat, and we recorded GPS coordinates of all traps as they were set. Traps were batched into deployments consisting of three camera-equipped traps (control, pre-stocked with green crab, or pre-stocked with rock crab: see below) and two traps without cameras. Every trap was baited before each deployment with equal amounts of frozen herring (about one half of a large fish) in bait bags tied inside the "kitchen" (a gear-specific term for the entrance compartment, Figure 2A). Soak durations (i.e. the time between deployment and retrieval) were approximately $24 \mathrm{~h}$ and traps were set $\sim 50 \mathrm{~m}$ apart horizontally. No other fishing activity occurred in the vicinity of our experiment. Upon retrieving each trap, we measured the size (carapace length- tip to tip) and sex of every lobster captured. All lobster were released where caught. We counted the number of crabs caught in the trap, and retained the green crab to be euthanized on shore in accordance with Memorial University's animal care protocol. All traps were re-baited and re-deployed within the study area. In total, we conducted 17 deployments (with five traps per deployment, total $n=85$ ).

The project was approved as a 'Category A' study by the Institutional Animal Care Committee at Memorial University as it involved invertebrates (project \# 15-02-BF), and all field research was conducted under experimental license NL-3271-16 issued by Fisheries and Oceans Canada. 


\subsection{Pre-stocking field experiment}

To determine the influence of crabs (both native and invasive) inside the trap on

subsequent lobster entries, we 'pre-stocked' two of the three camera-equipped traps with either seven native rock crabs (Cancer irroratus) or seven invasive green crabs (Carcinus maenas) tethered inside the kitchen. The density of pre-stocked crabs (seven per trap) was selected to impose a strong effect of crabs (green crab and rock crab) entering the traps in volumes, replicating conditions observed in previous field studies at sites with higher densities of green crab than those observed in our study area. The technique of tethering has been described in previous studies, and is commonly used to evaluate behavioural interactions among species (Wahle and Steneck, 1992; Watson and Jury, 2013). We tethered the crabs using fine fishing line looped around the rear two legs of the crab and tied (leash-like) to split metal rings attached to the wire cells on the top of the kitchen (Figure 2A). This allowed crabs to move freely around the kitchen without being able to exit the trap. The third camera trap served as a control and was not pre-stocked with any crabs. We captured the green crab used for pre-stocking with Fukui traps in intertidal areas bordering the sites where we deployed our lobster traps. We collected rock crab via SCUBA from areas adjacent to deployment sites. All tethered crabs (both green crab and rock crab) had carapace widths $>5 \mathrm{~cm}$ (measured point to point). Each crab was used in only a

173 single experimental trial, and was either destroyed (green crab) or returned to the site from which 174 they were collected (rock crab) on conclusion of the trial. 
177 deployments (one dive per trap, $\mathrm{n}$ dives $=33$ ). Within each dive, divers recorded the depth at

178 which the trap was deployed, and collected data along four transects oriented North, South, West 179 and East of each trap (Figure 2B).

the survey swimming side-by-side, where one diver reeled out the transect line, orienting in one of the four cardinal directions, while the other diver swam alongside simultaneously and recorded counts of lobster, green crab and rock crab within two metres of the transect line up to the end of the transect at $25 \mathrm{~m}$. After $25 \mathrm{~m}$ the divers swam back to the trap and reeled in the transect tape. This process was repeated, orienting in the remaining three directions. We repeated this for each camera trap, for a total surveyed area of $200 \mathrm{~m}^{2}$ per trap, and $600 \mathrm{~m}^{2}$ per deployment.

\subsection{Video analysis:}

We collected approximately $663 \mathrm{~h}$ of underwater video footage across 17 deployments.

Following the field study, we scored the videos manually, following protocols described in previous literature (Favaro et al., 2012; Jury et al., 2001; Meintzer et al., 2017). Specifically, we recorded the following quantitative parameters for lobster, rock crab and green crab: (1) the number, direction and duration of entry attempts as well as the proportion of those entries that were successful versus failed, (2) the number, direction and duration of exits from the trap, (3) the time spent feeding on the bait, (4) the number and duration of interspecific aggression events, and (5) the number and duration of predation events. 
We defined an entry attempt as an instance where more than half the individual's body

198

199

200

201

202

203

204

205

206

207

208

209

210

211

212

213

214

215

216

217

218 length crossed into the trap. The result and duration of each attempt was scored as either failed, where the individual retreated outside the trap, or as a success, where the individual's body crosses entirely into the trap. Individuals could enter/exit the trap through the entrance, through the wire cells in the trap kitchen and parlour (Figure 2A), or through the escape slats in the top and bottom of the trap. Note, each entry attempt was considered 'new' given that individuals were not individually identifiable, thus we assume that some individuals were counted multiple times.

We defined interspecific aggression as agonistic behaviours involving individuals engaging in threat displays including a meral spread (chelae raised and held laterally, outwards from the body), or any physical contact including touching and grasping actions (Haarr and Rochette, 2012; Rossong et al., 2006). We defined predation as behaviours involving one individual being consumed by another. For each predation event observed, we visually estimated the claw size of the predator(s) relative to a fixed point on the trap of known length $(3.8 \mathrm{~cm}$ wire cells) using Adobe Photoshop. We assigned lobsters into bins of small, medium, and large, with estimated claw sizes being below $6 \mathrm{~cm}$, between $6 \mathrm{~cm}$ and $8 \mathrm{~cm}$, or above $8 \mathrm{~cm}$, respectively.

\subsection{Statistical Analysis - Catch data}

In this paper we use the software package R (R Core Team, 2015). We carried out data exploration in accordance with the protocol described in (Zuur et al., 2010).

To model lobster catch as a function of the covariates a Poisson generalized linear mixedeffects model (GLMM) with a log link function was used. GLMMs can handle data that violates assumptions required for simple linear models and are therefore a common technique for

Peer) reviewing PDF | (2019:01:34310:2:0:NEW 13 Dec 2019) 
219 analyzing ecological data (Zuur et al., 2009). The Poisson distribution is typically used for count

220 data and the log link function ensures positive fitted values, and if the Poisson GLMM is

221 overdispersed, a negative binomial model can be used instead (Zuur and Ieno, 2016). Fixed

222 covariates in our full model are trap pre-stocking condition (categorical, four levels: unstocked,

223 green crab pre-stock, rock crab pre-stock, no camera/unstocked) and soak duration (continuous)

224 [Equation (1)]. We included an interaction term between trap pre-stocking condition and soak

225 duration. We included deployment number (1-17) as a random effect. As we only had fine-scale

226 depth data for 11/17 deployments, we could not include it as a covariate, so we created

227 exploratory plots to assess whether relationships existed between lobster catch and deployment

228 depth (Supplementary Figure 1).

229

230

231

232

233

234

235

236

237

238

239

240

We then conducted stepwise model simplification, sequentially dropping non-significant

terms until all terms in the model were statistically significant (procedure outlined in Crawley, 2012). This procedure was used for all models presented in this paper, and we used the lme 4 package (Bates et al., 2017) to fit models. We verified model assumptions by plotting residuals against fitted values. Residuals met assumptions for normality, homogeneity and independence, and there was no evidence of overdispersion. We interpreted reduced models.

$\mathrm{E}\left(\right.$ LobsterCatch $\left._{\mathrm{ij}}\right)=\mu_{\mathrm{ij}}$

$\log \left(\mu_{\mathrm{ij}}\right)=$ TrapPrestockingCondition $_{\mathrm{ij}}+$ SoakDuration $_{\mathrm{ij}}+$ TrapPrestockingCondition $_{\mathrm{ij}} \mathrm{x}$ SoakDuration $_{\mathrm{ij}}+$ Deployment $_{\mathrm{i}}$ 

with fixed covariates of prestocking condition, soak duration, and a prestocking by soak duration interaction, with deployment as a random effect [full model; Equation (2)].

We used a negative binomial GLMM to test the fixed effect of trap pre-stocking

257 distribution.

$$
\text { EntryTime }_{\mathrm{ij}} \sim \mathrm{NB}\left(\mu_{\mathrm{ij}} \text {, theta }\right)
$$

$$
\mathrm{E}\left(\text { EntryTime }_{\mathrm{ij}}\right)=\mu_{\mathrm{ij}}
$$


261

262

263

264

265

266

267

268

269

270

271

272

273

274

275

276

277

278

279

280

281
$\operatorname{Var}\left(\right.$ EntryTime $\left._{\mathrm{ij}}\right)=\mu_{\mathrm{i}}+\left(\mu_{\mathrm{i}}^{2} /\right.$ theta $)$

$\log \left(\mu_{\mathrm{ij}}\right)=$ TrapPrestockingCondition $_{\mathrm{ij}}+$ Deployment $_{\mathrm{i}}$

Deployment $_{\mathrm{i}} \sim N\left(0, \sigma^{2}\right)$

(eqn 3)

To examine whether there was an association between trap pre-stocking condition and the proportion of successful versus failed entry attempts by lobster, we used the prop.test function in $\mathrm{R}$ which uses Pearson's chi-squared test statistic to test the null that the proportions (probabilities of success) in several groups are the same (R Core Team, 2015).

\subsection{Statistical Analysis - SCUBA data}

The SCUBA-based transect survey component of our study provided a context for what we observed in our catch and video data and allowed us to obtain estimates of lobster density that were temporally matched to the video and trap catch data. We used a GLMM to measure the impact of the ambient lobster density (continuous) and trap pre-stocking condition (categorical, four levels) on lobster catch, and an interaction between pre-stocking condition and density [Equation (4)].

The distribution of our catch data was best explained by a Poisson distribution. We simplified the model using stepwise removal of non-significant terms (Crawley, 2012) and fit the model using the lme4 package (Bates et al., 2017). We plotted residuals versus fitted values to verify the model assumptions. Residuals met the assumptions for normality, homogeneity and independence, and there was no evidence of overdispersion.

$$
\operatorname{LobsterCatch}_{\mathrm{ij}} \sim \operatorname{Poisson}\left(\mu_{\mathrm{ij}}\right)
$$


282

283

284

285

286

287

288

289

290

291

292

293

294

295

296

297

298

299

300

301

$\mathrm{E}\left(\right.$ LobsterCatch $\left._{\mathrm{ij}}\right)=\mu_{\mathrm{ij}}$

$\log \left(\mu_{\mathrm{ij}}\right)=$ TrapPrestockingCondition $_{\mathrm{ij}}+$ AmbientLobster $_{\mathrm{ij}}+$ TrapPrestockingCondition $_{\mathrm{ij}} \mathrm{X}$ AmbientLobster $_{\mathrm{ij}}+$ Deployment $_{\mathrm{i}}$

Deployment $_{\mathrm{i}} \sim \mathrm{N}\left(0, \sigma^{2}\right)$

(eqn 4)

To examine whether there was an association between trap pre-stocking condition and the proportion of successful versus failed entry attempts by lobster for deployments where video data and SCUBA data were temporally matched, we used the prop.test function in R.

\section{Results}

\subsection{Catch data}

Across 85 individual trap deployments soak durations ranged between 15.2 and $26.6 \mathrm{~h}$ $($ mean $\pm 1 \mathrm{SD}=21.9 \pm 3.1)$. We did not detect a relationship between soak duration and the number of lobster caught across pre-stocking conditions (Supplementary Figure 2). Similarly, we found no relationship between depth and either lobster catch or carapace length (Supplementary Figures 1 and 3).

We caught a total of 326 lobsters, six green crabs, and three rock crabs across the entire study. Traps pre-stocked with green crab caught between $47 \%$ fewer, and $1.97 \%$ more lobster than unstocked traps $(95 \%$ C.I.; $\beta=-0.312$, S.E. $=0.168, p=0.064$; Figure 3A; Table 1). Traps pre-stocked with rock crab caught between 54\% and $8.9 \%$ fewer lobster than unstocked traps, $(95 \%$ C.I.; $\beta=-0.436$, S.E. $=0.175, p=0.013$; Figure 3A; Table 1). 
We found no significant impact of the presence of the camera apparatus on lobster catch

303 (GLMM: No camera, $\beta=-0.225$, S.E. $=0.140, z=-1.610, p=0.107$; Figure 3A; Table 1). Soak

304 duration did not significantly influence this relationship and was removed from the model via

305 stepwise reduction. Model validation indicated our choice of model was appropriate through

306 visual inspection of residuals. The model had a dispersion parameter of 1.1, indicating it was not

307 overdispersed.

Lobster size (carapace length) ranged from 48 to $98 \mathrm{~mm}($ mean $\pm 1 \mathrm{SD}=80.4 \pm 6.1 \mathrm{~mm})$.

309

310

311

312

313

314

315

316

317

318

319

320

321

322

323

\subsection{Video data}

Of the $663 \mathrm{~h}$ of underwater video footage collected across 17 deployments, $452 \mathrm{~h}$ had adequate ambient lighting for analysis. We analyzed the same amount of video $(\sim 150 \mathrm{~h})$ for each trap pre-stocking condition.

Across all videos we observed a total of 3,801 lobster entry attempts across all traps. There were 1,625 entry attempts in unstocked traps, 1,119 in traps pre-stocked with green crab, and 1,057 in traps pre-stocked with rock crab. The proportion of these attempts that resulted in successful entry differed across pre-stocking condition (unstocked: 69.7\%, green crab: 45.3\%, rock crab: 49.8\%). We observed 1,070 lobsters exiting from unstocked traps, 409 exiting from traps stocked with green crab, and 494 exiting from traps stocked with rock crab (Figure 4).

Because we could not identify individual lobsters, we tracked raw number of entries and exits (e.g. if a lobster did a successful entry attempt, exited, and then re-entered, it would be counted as two entries and one exit). 
When we accounted for lobster entry attempts through the entrance only (i.e., excluding

325

326

327

328

329

330

331

332

333

334

335

336

337

338

339

340

341

342

343

344

345

346

small individuals that attempted entries through the wire cells and escape slats) we found $30.1 \%$

$(\mathrm{N}=139)$ were successful in the unstocked trap, while $17.1 \%(\mathrm{~N}=106)$ and $17.7 \%(\mathrm{~N}=105)$ of entry attempts were successful for green crab and rock crab pre-stocked traps, respectively (Figure 5).

The proportion of successful entries was higher in the unstocked traps than in either the green crab or rock crab pre-stocked traps for all lobster attempts $\left(\mathrm{x}^{2}=190.072, \mathrm{df}=2, \mathrm{p}<0.001\right.$; Figure 6A) as well as for those only through the trap entrance $\left(x^{2}=36.049, \mathrm{df}=2, \mathrm{p}<0.001\right.$; Figure 6B). Smaller lobster were able to easily crawl through the wire cells on the kitchen and parlour sides of the trap, as well as through the escape slats on the top and bottom of the trap. We did not observe any difference in the proportion of successful entries across trap pre-stocking conditions for attempts made by small lobster through the wire cells or escape slats (Figure 6C).

We did not detect any difference in the duration of successful lobster entry attempts through the trap entrances according to trap pre-stocking condition (Supplementary Figure 4; Table 2).

There was little difference between the number of lobster inside traps after a full deployment versus at the end of the video analysis period for each trap pre-stocking condition (mean difference $\pm 1 \mathrm{SD}=$ unstocked, $1.2 \pm 2.5$; green crab pre-stock, $-0.3 \pm 2.9$; rock crab prestock, $-0.5 \pm 2.5$; Supplementary Figure 5).

We observed very few green crab or rock crab entering traps in any stocking condition. We observed 45 entry attempts made by green crab, of which 27 were successful. Rock crab made 18 entry attempts, of which 17 were successful. Green crab and rock crab were observed exiting the camera traps 19 and 13 times respectively. All these crabs occurred in just two deployments, meaning we observed no crab entry in most videos. 
We observed 60 events in which lobster consumed all or part of another organism while

348 in the trap. There were 36 predation events against tethered rock crab, 20 against tethered green

349 crab, and four against other lobster. Lobsters that engaged in predation activities tended to have

350 larger claw sizes than those that did not predate on pre-stocked rock crab, green crab, or lobster

351 (Supplementary Figure 6).

352

353

354

355

356

357

358

\subsection{SCUBA Surveys:}

Lobster catch was positively associated with changes in the density of lobster in the vicinity of the trap (GLMM: ambient lobster, $\beta=0.016$ S.E. $=0.007, \mathrm{z}=2.258, \mathrm{p}=0.024$;

Supplementary Figure 7; Table 3). Trap pre-stocking condition did not significantly influence this relationship and was removed from the model via stepwise reduction. Model validation indicated our choice of model was appropriate and the model had a dispersion parameter of 0.95 , indicating it was not overdispersed. The output from the model is provided in Table 3.

The number of ambient lobster ranged from 5 to $50($ mean $\pm \mathrm{SD}=21.97 \pm 11.24)$, ambient green crab ranged from 0 to $8($ mean $\pm \mathrm{SD}=0.27 \pm 1.40)$, and ambient rock crab ranged from 0 to 9 (mean $\pm \mathrm{SD}=1.70 \pm 2.05)$. Densities of lobster, green crab and rock crab determined by SCUBA surveys ranged from 0.025 to 0.25 lobster $/ \mathrm{m}^{2}, 0$ to 0.04 green $\mathrm{crab} / \mathrm{m}$-squared, and 0 to 0.045 rock crab $/ \mathrm{m}^{2}$.

The average number of ambient lobster did not vary significantly across trap pre-stocking conditions (mean $\pm 1 \mathrm{SD}=$ unstocked, $23.0 \pm 12.57$; green crab pre-stock, $21.18 \pm 12.80$; rock crab pre-stock $21.73 \pm 8.97$; Figure 7). 


\section{Discussion}

370

The goal of this study was to determine whether the presence of green crab inside lobster

371

372

373

374

375

376

377

378

379

380

381

382

383

384

385

386

387

388

389

390

traps and in the vicinity of deployed traps influenced the trap's lobster catch rate. Our study

demonstrated that 1) the presence of both green crab and native rock crab impacted the total

number of lobster that attempted to enter the trap and the number that successfully entered, 2)

lobster can predate on green crab, rock crab and other lobster inside traps and 3) there is a

positive association between lobster catch and ambient lobster density.

\subsection{Catch Data}

We found traps pre-stocked with both species of crabs caught fewer lobster than unstocked traps, though the reduction associated with green crab was not technically statistically significant $(\mathrm{p}=0.06)$.

The number of green crab observed around our traps via SCUBA surveys were relatively

low. As a result, we were not able to robustly assess the relationship between ambient green crab density and lobster catch rates. Since completing this study, the density of green crab in Fortune

Bay has increased (C. McKenzie, Pers. Obs.). Repeating this study in an area with a higher density of invaders may yield additional insight.

The sizes of captured lobster in our study were similar across all trap pre-stocking conditions and the majority were of sub-legal size $(<82.5 \mathrm{~mm})$. Given that our fieldwork was conducted after closure of the commercial fishery, it is possible that fewer legal sized $(>82.5$ $\mathrm{mm}$ ) lobster were available to be captured. Previous studies have found that the presence of larger individuals inside traps can reduce the catch of smaller individuals for lobster (Watson and Jury, 2013) as well as for green crab and rock crab (Miller and Addison, 1995). Watson and Jury, 
391 (2013) suggest that this may be mediated by bait guarding, particularly when smaller individuals

392 attempt to enter the trap. Given that adult lobster are much larger than the pre-stocked green crab

393 and rock crab, it is perhaps unsurprising that we did not observe a difference in average lobster

394 size across pre-stocking condition from our catch data.

We did not detect a relationship between the duration of time a trap was soaking in the water and the number of lobster caught across trap pre-stocking condition (Figure 5). Our underwater video camera allowed us to observe and quantify the accumulation of lobster over the first 13 hours of trap deployments, after which the camera would turn off and the trap would be left to soak until retrieval the following day. We did not observe more lobster captured at the end of the deployment ( $24 \mathrm{~h}$ soak period) versus at the end of the video observation duration (13 $\mathrm{h}$ ) for any of the trap pre-stocking conditions. Our results are in general agreement with those of Miller and Rodger, (1996), who found traps retrieved more than twice in a 24 hour period captured more lobster than those retrieved only once due to trap saturation.

\subsection{Video Data}

The ambient density of green crab was low, and in many videos we saw none at all in this area that was recently-invaded at the time of the study. As a result, we did not find support for the hypotheses that green crab invade the trap and either 1) deplete the bait, 2) impede entry and/or 3) force lobster to exit the trap (increased escapement). deplete the bait in these traps. Chemical signals released by conspecifics, competitors, predators, and mates, as well as internal motivational states (e.g., activity level, moult stage, reproductive

412 status, hunger level), and environmental factors (e.g., flow, temperature, light intensity, 
413 photoperiod), may contribute to the sensitivity of green crab to feeding stimulants (Atema, 1995,

414 1985; Breithaupt and Atema, 2000; Hayden et al., 2007; Hazlett, 2003; Hazlett et al., 2006;

415 Moore and Howarth, 1996; Sneddon et al., 2003; Zimmer-Faust et al., 1996; Zimmer-Faust,

416 1991, 1989). Further, a laboratory study conducted by Fletcher and Hardege (2009) found that

417 male green crab took significantly longer to respond to food stimuli as a result of agonistic

418 encounters. Given the complexity of chemoreception in its mediatory role of feeding behavior in

419 marine crustaceans, we were unable to investigate the influence of tethering on the feeding

420 response of pre-stocked green crab in the field.

Our finding that the proportion of successful lobster entries were reduced in crab-stocked

422 traps aligns with other pre-stocking (Richards et al., 1983) and field studies (Jury et al., 2001)

423 that suggest interactions between lobster inside and outside traps can strongly limit lobster entry

424 and catch. Jury et al., (2001) found that only $11 \%$ of lobster entry attempts were successful when

425 the kitchen was occupied versus $64 \%$ when the kitchen was vacant. In addition, they note that

426 entry attempts may also be influenced by competition outside the trap where both lobster and

427 crab have been observed competing aggressively for trap entry (Jury et al., 2001). We did not

428 observe any instances of interactions between untethered crabs and lobster during entry attempts.

429 This is likely due to the low density of crabs around traps as observed via our SCUBA surveys.

430 Interestingly, we did not detect any difference between crab pre-stocked traps and unstocked

431 traps for attempts made by small lobster through wire cells and escape slats. This could be

432 attributed to smaller lobster having more opportunities to enter the trap (through the top and

433 bottom escape slats, and the $3.8 \mathrm{~cm}$ wire cells on the kitchen and parlour sides of the trap),

434 whereas larger lobster could only enter through the trap entrance (where they would directly

435 encounter the pre-stocked crabs in the trap kitchen). Small lobster may therefore have been less 
436 likely to interact with/directly encounter the pre-stocked crabs as these were tethered in the trap 437 kitchen only.

We found lobster did not take substantially longer to complete a successful entry through

439 the entrance into crab pre-stocked traps compared to unstocked traps. Our video data provided no 440 evidence to suggest that lobster entry was physically impeded by the presence of rock crab or 441 green crab, rather fewer lobster attempted to enter traps where crabs were present. Furthermore, 442 our dive data show that this was not a consequence of lower lobster density around the crab pre443 stocked traps.

Results from various laboratory experiments have suggested that the odor of trapped crab and lobster could repel individuals that might otherwise be attracted to either the bait or the trap as a shelter (Miller, 1978). It is possible that these factors were occurring but we were not able to 447 detect them from our video and SCUBA analyses. Importantly, we recorded all videos during daylight hours where ambient light was sufficient to make observations. As a result, we were not able to assess interactions that occurred overnight. While previous research suggests that lobster may be more active during the night, in a preliminary field study conducted in 2015 we did not find a substantial difference in lobster catch between traps deployed during the daytime compared to traps deployed at night.

453 Furthermore, a field study by Jury et al., (2001), found no evidence that lobster will enter traps 454 more often during the night. Our data concur with these findings, as we found our catch data 455 (daytime and nighttime) did not significantly differ from our video data, captured during the 456 initial 13 hours of trap deployment (daytime). 
458 fewer lobster than unstocked traps, though the reduction due to green crab was not statistically

459 significant $(\mathrm{p}=0.06)$. Our video data demonstrated that when traps were pre-stocked with crabs,

460 successful entries as well as entry attempts of lobster were significantly reduced. Our trap

461 deployments collated 85 observations of catch data and recorded 452 hours of underwater video

462 data which was analysed to produce around 10,000 individual observations. This provides a

463 compelling difference between the breadth of information we can glean from 85 observations of

464 catch data as compared to 452 hours of in-depth video analysis. Taken together, the results from

465 our catch and video data, suggest that while there is a relationship between in-trap crab density

466 and trap effectiveness, it is not linked to the non-native/native status of the crab species.

467 Although, if the number of green crab are significantly higher due to invasion status then it

468 would be more likely that green crab would be the crab in the trap interacting with the lobster,

469 particularly if they are replacing the native rock crab.

Previous laboratory studies have demonstrated that predation is possible between lobster

and green crab (Goldstein et al., 2017). Our study is the first to provide evidence of this dynamic

some instances, pre-stocked crabs were consumed in preference to a full bait bag. It is important

474 to note that crabs in our study were tethered inside traps and were not able to flee from

476 a large body of literature on agonistic behaviours in crustaceans showing that the larger animal

477 typically dominates in aggressive contests (Dingle, 1983; Hyatt, 1983; Rossong et al., 2006).

478 Interestingly, our underwater video also enabled us to observe multiple events of cannibalism

479 where trapped adult lobster were dismembered and consumed by other lobster in the parlour of 
480 the trap. In previous laboratory trials Haarr and Rochette, (2012) found that at high densities

481 juvenile lobster (20-45 mm carapace length) would consume conspecifics. However, they did not

482 observe juvenile lobster predating on green crab.

483

484

485

486

487

488

489

490

491

492

493

494

495

496

497

498

499

\subsection{SCUBA surveys}

Due to the low ambient density of green crab observed via our SCUBA surveys we were unable to test whether green crab-induced reductions of lobster catch would be more severe where ambient green crab density was higher. Nevertheless, our SCUBA surveys provided us with two pieces of information that contextualize our results. First, there is a positive relationship between lobster catch and the density of lobster around the traps, which is consistent with a field study by Watson and Jury (2013). Second, we did not detect any difference in the mean density of lobster around traps in each pre-stocking condition (Figure 7), implying that any differences we detected were due to pre-stocking condition and dynamics that occurred within the trap, rather than being a result of different lobster densities in regions in which traps were deployed.

We believe the low ambient densities of green crab observed during our SCUBA surveys represented actual low densities, and were not an artifact of low detection probability.

While detection probability can vary across species (Tremblay and Smith, 2001), we restricted dives to daylight hours and our sites were composed of sand and small cobble, which provided a high contrast background against which we were able to detect these species.

\subsection{Procedural Control}



response to both green crab and rock crab was similar, it demonstrated impacts on lobster catch were not specific to green crab but were rather due to the presence of either crab species in the traps. This finding aligns with those of Howard et al., (2017) which found non-native crabs did not reduce prey abundance via direct consumption any more than native crabs. Howard et al., (2017) also reported on the paucity of studies that directly compared impacts of native versus non-native species. Had we not incorporated a procedural control, our conclusion would likely have been that green crab caused declines in trap effectiveness, with the implication that something about their identity as an invader was the root cause. We recommend future studies investigating green crab impacts incorporate a direct comparison with the impacts of native species. In some cases, it may be the nature of the invasion (e.g. rapid population growth) rather

511 than the identity of the species that causes impacts. crab have been observed readily accessing and being captured by lobster traps (Goldstein et al.,

515 2017). In the Great Bay Estuary, New Hampshire, Goldstein et al., (2017), captured 8.5 times 516 more green crab than lobster. This implies that reductions in catch rates may not be due to a 517 specific unique quality of the invader but rather the sheer abundance of green crab relative to 518 native species. 
521 This study has shown the presence of crabs inside lobster traps can reduce the effectiveness of

522 lobster traps. Crabs in traps cause fewer lobster to attempt entry, and reduce the success rate of

523 entries. This effect was observable with both native and invasive crabs. Using SCUBA survey

524 data we determined the difference could not be explained by differences in ambient lobster

525 density across stocking conditions.

526 As green crab spread in extent and grow in density around Newfoundland (DFO, 2016), it will

527 become increasingly important to understand how the invasion is specifically affecting fishery

528 performance. As the density of green crab increases, there will be more potential for fishery

529 interactions. While the collapse of lobster catch rates in neighbouring Placentia Bay pre-date the

530 green crab invasion (and so cannot be blamed on green crab alone (Best et al., 2017; DFO,

531 2018)), the lack of recovery in this heavily-invaded system may signal a warning to fisheries in

532 the Fortune Bay region - that if green crab continue to grow in abundance, it is likely traps will

533 continue to perform worse. While ecosystem responses to invasion must continue to be studied,

534 future research should also examine fishing gear performance across gradients of invader density

535 to better understand how invaders can impact the capture process itself.

\section{5. Acknowledgements}

The authors thank the MUN Field Services team for their logistical support and assistance in the field. We thank staff at the Marine Institute's Centre for Sustainable Aquatic

540 Resources (Terry Bungay and George Legge) for assistance in constructing and testing the

541 camera apparatus. We acknowledge Jonathan Bergshoeff for supporting the work, and Kyle 
542 Matheson for assistance with local site information and contacts. The authors wish to thank

543 Kiley Best and Stephanie Green for helpful comments to improve this manuscript.

\section{Funding}

This project was funded by a Marine Environmental Observation Prediction and

Response (MEOPAR) Early-Career Faculty Development Grant awarded to BF (EC1-BF-

Development Corporation of Newfoundland and Labrador (5404-1914-101). Funding was also

provided by the Canadian Centre for Fisheries Innovation (H-2015-06), and the Newfoundland

no role in the study design, data collection and analysis, publication decision, or preparation of the manuscript.

\section{References}

557

559

560

561

562

563

564

565

566

567

568

Albins, M.A., Hixon., M.A., 2008. Invasive Indo-Pacific lionfish Pterois volitans reduce recruitment of Atlantic coral- reef fishes. Mar. Ecol. Prog. Ser. 367, 233-238.

Atema, J., 1995. Chemical signals in the marine environment: dispersal, direction, and temporal signal analysis. Eisner, T., Meinwald, J. (Eds.), Chem. Biot. Interact. Nat. Acad. Press. Washington, DC. $147-159$.

Atema, J., 1985. Chemoreception in the sea: adaptations of chemoreceptors and behaviour to aquatic stimulus conditions. Soc. Exp. Biol. Symp. 39, 387-423.

Bates, D., Mächler, M., Bolker, B., Walker, S., Christensen, R., Singmann, H., Dai, B., Grothendieck, G., Green, P., 2017. Package "lme4". R package version 1.1-13. https://doi.org/https:// github.com/lme4/lme4/.

Behrens Yamada, S., 2001. Global Invader: The European Green Crab. Oregon Sea Grant, Corvallis.

Bergshoeff, J.A., Zargarpour, N., Legge, G., Favaro, B., 2017. How to build a low-cost underwater 
569

570

571

572

573

574

575

576

577

578

579

580

581

582

583

584

585

586

587

588

589

590

591

592

593

594

595

596

597

598

599

600

601

602

603

604

605

606

607

608

609

camera housing for aquatic research. Facets 2, 1-10. https://doi.org/10.1139/facets-2016-0048

Best, K., McKenzie, C.H., Couturier, C., 2017. Reproductive biology of an invasive population of European green crab, Carcinus maenas, in Placentia Bay, Newfoundland. Manag. Biol. Invasions 8247-255 DOI 10.3391/mbi.2017.8.2.12.

Blakeslee, a. M.H., McKenzie, C.H., Darling, J. a., Byers, J.E., Pringle, J.M., Roman, J., 2010. A hitchhiker's guide to the Maritimes: Anthropogenic transport facilitates long-distance dispersal of an invasive marine crab to Newfoundland. Divers. Distrib. 16, 879-891. https://doi.org/10.1111/j.14724642.2010.00703.x

Breithaupt, T., Atema, J., 2000. The timing of chemical signaling with urine in dominance fights in lobsters Homarus americanus. Behav. Ecol. Sociobiol. 49, 67-78.

Carlton, J.T., Cohen, A.N., 2003. Episodic global dispersal in shallow water marine organisms: The case history of the European shore crabs Carcinus maenas and C. aestuarii. J. Biogeogr. 30, 1809-1820. https://doi.org/10.1111/j.1365-2699.2003.00962.x

Crawley, M.J., 2012. The R Book. John Wiley \& Son, West Sussex.

DeGraaf, J.D., Tyrrell, M.C., 2004. Comparison of the feeding rates of two introduced crab species, Carcinus maenas and Hemigrapsus sanguineus, on the Blue Mussel, Mytilus edulis. Northeast. Nat. $11,163-167$.

DFO, 2018. Lobster Landings (1995-present), Newfoundland and Labrador. https://doi.org/https://doi.org/10.6084/m9.figshare.5844423.v2

DFO, 2016. Assessment of American Lobster in Newfoundland. DFO Can. Sci. Advis. Sec. Sci. Advis. Rep. 2016/052.

DFO, 2011. Ecological Assessment of the Invasive European Green Crab (Carcinus Maenas) in Newfoundland 2007-2009. Can. Sci. Advis. Secr. Sci. Advis. Rep. 2010.

Dingle, H., 1983. Stategies of agonistic behaviour in crustacea. In: Rebach, S., Dunham, D.W. (Eds.), Studies of Adaptation: The Behaviour of Higher Crustacea. Wiley, New York 85-111.

Favaro, B., Lichota, C., Côté, I.M., Duff, S.D., 2012. TrapCam: An inexpensive camera system for studying deep-water animals. Methods Ecol. Evol. 3, 39-46. https://doi.org/10.1111/j.2041210X.2011.00128.x

Fletcher, N., Hardege, J.D., 2009. The cost of conflict: agonistic encounters influence responses to chemical signals in the European shore crab. Anim. Behav. 77, 357-361.

Garbary, D.J., Miller, A.G., Williams, J., Seymour, N.R., 2014. Drastic decline of an extensive eelgrass bed in Nova Scotia due to the activity of the invasive green crab (Carcinus maenas). Mar. Biol. 161, 3-15. https://doi.org/10.1007/s00227-013-2323-4

Goldstein, J.S., Morrissey, E.M., Moretti, E.D., Watson, W.H., 2017. A comparison of the distribution and abundance of European green crabs and American lobsters in the Great Bay Estuary, New Hampshire, USA. Fish. Res. 189, 10-17. https://doi.org/10.1016/j.fishres.2017.01.002

Green, S.J., Akins, J.L., Maljković, A., Côté, I.M., 2012. Invasive lionfish drive Atlantic coral reef fish declines. PLoS ONE 7(3) e32596. https://doi.org/https://doi.org/10.1371/journal.pone.0032596

Haarr, M.L., Rochette, R., 2012. The effect of geographic origin on interactions between adult invasive green crabs carcinus maenas and juvenile American lobsters Homarus americanus in Atlantic Canada. J. Exp. Mar. Bio. Ecol. 422-423, 88-100. https://doi.org/10.1016/j.jembe.2012.04.016

Peer) reviewing PDF | (2019:01:34310:2:0:NEW 13 Dec 2019) 
610

611

612

613

614

615

616

617

618

619

620

621

622

623

624

625

626

627

628

629

630

631

632

633

634

635

636

637

638

639

640

641

642

643

644

645

646

647

648

649

650

Hayden, D., Jennings, A., Müller, C., Pascoe, D., Bublitz, R., Webb, H., Breithaupt, T., Watkins, L., Hardege, J., 2007. Sex-specific mediation of foraging in the shore crab, Carcinus maenas. Horm. Behav. 52, 162-168.

Hazlett, B.A., 2003. The effects of starvation on crayfish responses to alarm odor. Ethology 109, 587592.

Hazlett, B.A., Acquistapace, P., Gherardi, F., 2006. Responses of the crayfish Orconectes virilis to chemical cues depend upon flow conditions. J. Crust. Biol. 26, 94-98.

Howard, B.R., Therriault, T.W., Côté, I.M., 2017. Contrasting ecological impacts of native and nonnative marine crabs : a global meta-analysis. Mar. Ecol. Prog. Ser. 577, 93-103.

Hyatt, G.W., 1983. Qualitative and quantitative dimensions of crus- tacean aggression. In: Rebach, S., Dunham, D.W. (Eds.), Studies in Adaptation: The Behavior of Higher Crustacea. Wiley-Inter- Sci. Publ. New York, 113-139.

Jury, S.H., Howell, H., O’Grady, D.F., Watson, W.H., 2001. Lobster trap video: In situ video surveillance of the behaviour of Homarus americanus in and around traps. Mar. Freshw. Res. 52, 1125-1132. https://doi.org/10.1071/MF01096

Lowe, S., Browne, M., Boudjelas, S., De Poorter, M., 2000. 100 of the world's worst invasive alien species: A selection from the global invasive species database. Invasive Species Spec. Group, World Conserv. Union 12.

Matheson, K., McKenzie, C., Gregory, R., Robichaud, D., Bradbury, I., Snelgrove, P., Rose, G., 2016. Linking eelgrass decline and impacts on associated fish communities to European green crab Carcinus maenas invasion. Mar. Ecol. Prog. Ser. 548, 31-45. https://doi.org/10.3354/meps11674

Meintzer, P., Walsh, P., Favaro, B., 2017. Will you swim into my parlour? In situ observations of Atlantic cod (Gadus morhua) interactions with baited pots, with implications for gear design 1-18. https://doi.org/10.7717/peerj.2953

Miller, R.J., 1978. Entry of Cancer productus to baited traps. ICES J. Mar. Sci. 38, 220-225. https://doi.org/10.1093/icesjms/38.2.220

Miller, R.J., Addison, J.T., 1995. Trapping interactions of crabs and American lobster in laboratory tanks. Can. J. Fish. Aquat. Sci. 52, 315-324. https://doi.org/10.1139/f95-032

Miller, R.J., Rodger, R.S., 1996. Soak times and fishing strategy for American Lobster. Fish. Res. 26, 199-205. https://doi.org/10.1016/0165-7836(95)00445-9

Miron, G., Audet, D., Landry, T., Moriyasu, M., 2005. Predation potential of the invasive green crab (Carcinus maenas) and other common predators on commercial bivalve species found on Prince Edward Island. J. Shellfish Res. 24, 579-586.

Moore, P.G., Howarth, J., 1996. Foraging by marine scavengers: effects of relatedness, bait damage and hunger. J. Sea Res. 36, 267-273.

R Core Team, 2015. R: A language and environment for statistical computing. R Foundation for Statistical Computing, Vienna, Austria. http://www.r-project.org/.

Richards, R.A., Cobb, J.S., Fogarty, M.S., 1983. Effects of behavioral interactions on the catchability of American lobster, Homarus americanus, and two species of Cancer crab. Fish. Bull. 81, 51-60.

Rossong, M.A., Quijon, P.A., Williams, P.J., Snelgrove, P.V.., 2011. Foraging and shelter behavior of juvenile American lobster (Homarus americanus): The influence of a non-indigenous crab. J. Exp.

Peer] reviewing PDF | (2019:01:34310:2:0:NEW 13 Dec 2019) 
651

652

653

654

655

656

657

658

659

660

661

662

663

664

665

666

667

668

669

670

671

672

673

674

675

676

677

678

679

680

681

682

683

684

685

686

Mar. Bio. Ecol. 403, 75-80. https://doi.org/10.1016/j.jembe.2011.04.008

Rossong, M.A., Williams, P.J., Comeau, M., Mitchell, S.C., Apaloo, J., 2006. Agonistic interactions between the invasive green crab, Carcinus maenas (Linnaeus) and juvenile American lobster, Homarus americanus (Milne Edwards). J. Exp. Mar. Bio. Ecol. 329, 281-288. https://doi.org/10.1016/j.jembe.2005.09.007

Sneddon, L.U., Huntingford, F.A., Taylor, A.C., Clare, A., 2003. Female sex pheromone-mediated effects on behavior and consequences of male competition in the shore $\operatorname{crab}(<\mathrm{i}>\operatorname{Carcinus}$ maenas $<\mathrm{i} />)$. J. Chem. Ecol. 29, 55-70.

Tan, E.B.P., Beal, B.F., 2015. Interactions between the invasive European green crab, Carcinus maenas(L.), and juveniles of the soft-shell clam, Mya arenaria L., in eastern Maine, USA. J. Exp. Mar. Bio. Ecol. 462, 62-73.

Tremblay, M.J., Smith, S.J., 2001. Lobster (Homarus americanus) catchability in different habitats in late spring and early fall. Mar. Freshw. Res. 52, 1321-1331. https://doi.org/10.1071/MF01171

Wahle, R. a., Steneck, R.S., 1992. Habitat restrictions in early benthic life: experiments on habitat selection and in situ predation with the American lobster. J. Exp. Mar. Bio. Ecol. 157, 91-114. https://doi.org/10.1016/0022-0981(92)90077-N

Watson, W., Jury, S.H., 2013. The relationship between American lobster catch, entry rate into traps and density. Mar. Biol. Res. 9, 59-68. https://doi.org/10.1080/17451000.2012.727430

Williams, A.B., 1984. Shrimps, lobsters, and crabs of the Atlantic coast of the Eastern United States, Maine to Florida. Smithson. Inst. Press. D.C., USA.,.

Williams, P.J., Floyd, T. a., Rossong, M. a., 2006. Agonistic interactions between invasive green crabs, Carcinus maenas (Linnaeus), and sub-adult American lobsters, Homarus americanus (Milne Edwards). J. Exp. Mar. Bio. Ecol. 329, 66-74. https://doi.org/10.1016/j.jembe.2005.08.008

Zimmer-Faust, R.K., 1991. Chemical signal-to-noise detection by spiny lobsters. Biol. Bull. 181, 419426.

Zimmer-Faust, R.K., 1989. The relationship between chemoreception and foraging behavior in crustaceans. Limnol. Ocean. 34, 1367-1374.

Zimmer-Faust, R.K., O’Neill, P.B., Schar, D.W., 1996. The relationship between predator activity state and sensitivity to prey odors. Biol. Bull. 190, 82-87.

Zuur, A.F., Ieno, E.N., 2016. A protocol for conducting and presenting results of regression-type analyses 636-645. https://doi.org/10.1111/2041-210X.12577

Zuur, A.F., Ieno, E.N., Elphick, C.S., 2010. A protocol for data exploration to avoid common statistical problems. Methods Ecol. Evol. 1, 3-14. https://doi.org/10.1111/j.2041-210X.2009.00001.x

Zuur, A.F., Ieno, E.N., Walker, N., Saveliev, A.A., Smith, G.M., 2009. Mixed effects models and extensions in ecology with R. 1st Ed. New York Springer. 


\section{Figure 1}

Map of our study sites in Little Harbour East and Little Bay East, Fortune Bay, off the southern coast of Newfoundland.

(A) Study sites in Little Harbour East and Little Bay East, Fortune Bay. (B) Our study sites relative to the rest of Newfoundland. Black points indicate where we deployed our traps. Red squares indicate the location of our study sites relative to the rest of Newfoundland. Map A and B imagery (c) 2017 Google.

A

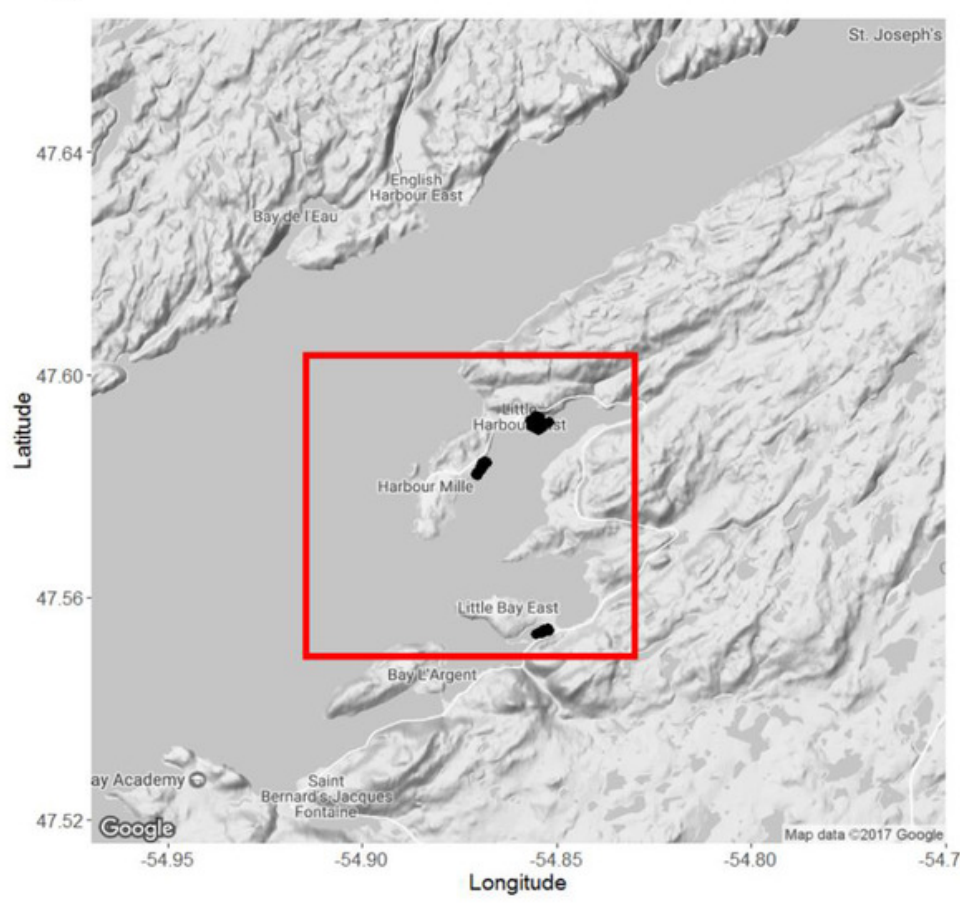

B

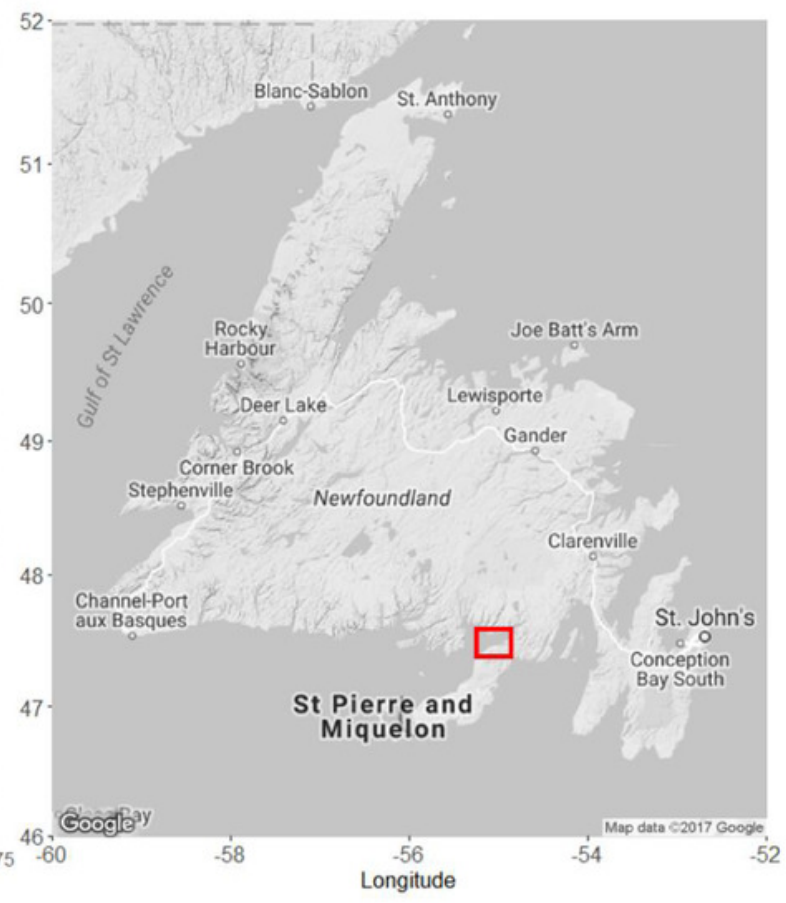




\section{Figure 2}

Top-down view of a green crab pre-stocked camera trap and SCUBA transects conducted on camera traps.

(A) The mesh entrance funnel leads into the kitchen compartment where the bait bag is stored and where 7 crabs were tethered using fishing line tied to split metal rings that were attached to wire cells on the top of the trap. The parlour refers to the area where lobsters are retained. (B) Dotted lines indicate the $25 \mathrm{~m}$ transects, oriented North, South, West and East of the camera trap (shown in the centre of the image). The $2 \mathrm{~m}$ marking indicates the area in which divers recorded counts of green crab, lobster and rock crab. 


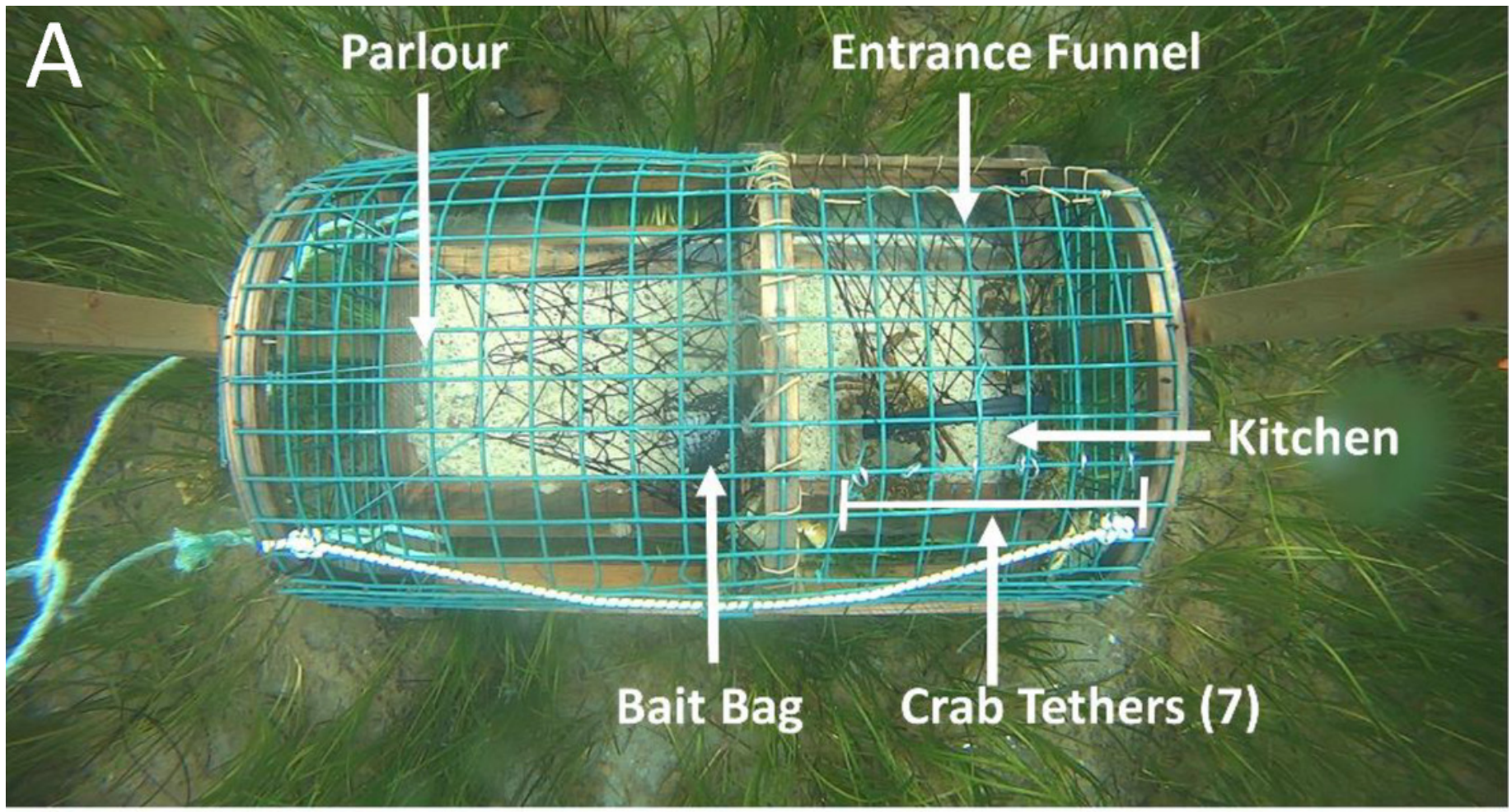

B

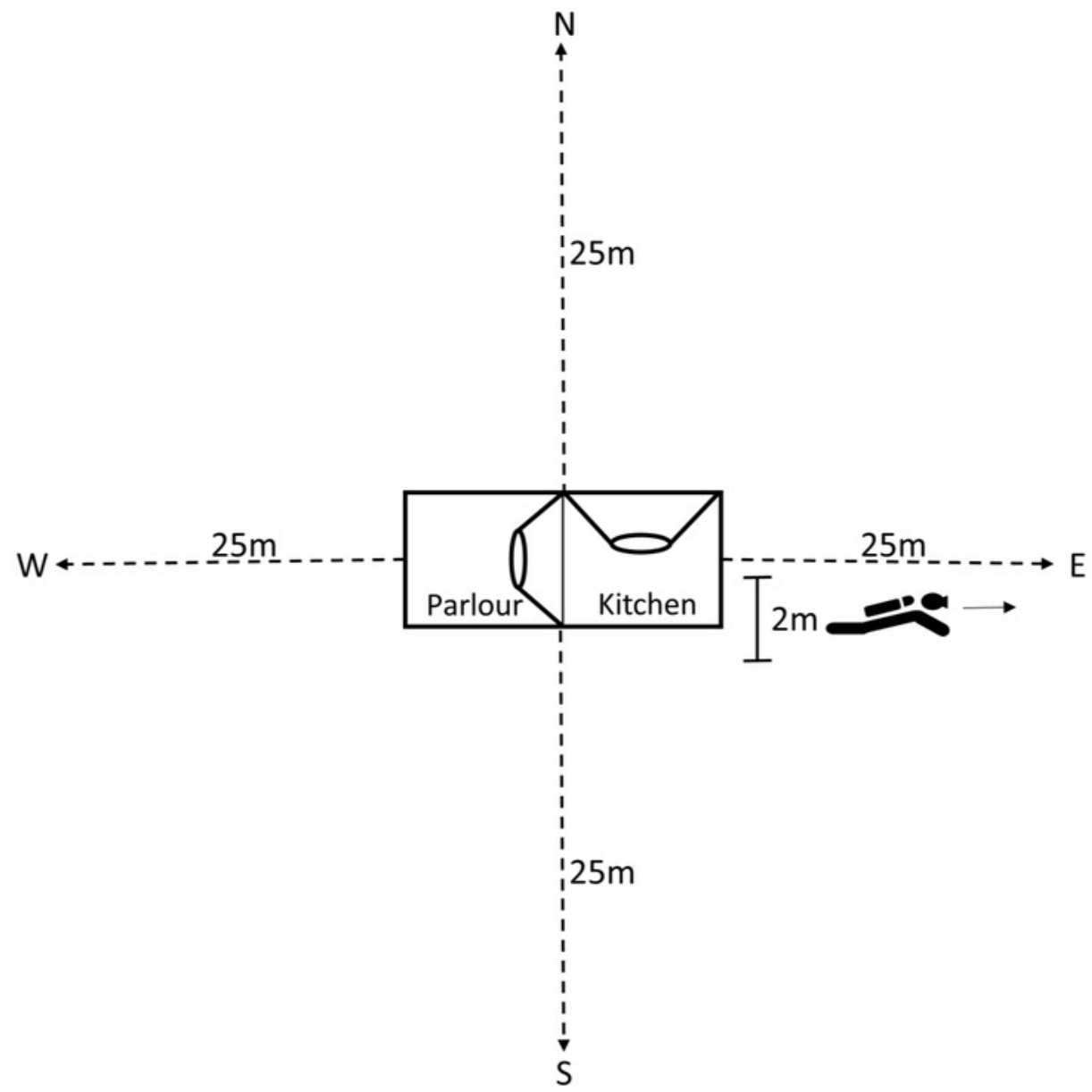


Figure 3

Boxplots comparing total lobster catch and average lobster size to trap pre-stocking condition.

(A) the distributions of total lobster catch according to trap pre-stocking condition (B) the distributions of average lobster size (carapace length) across trap pre-stocking conditions (the dotted red line indicates the minimum legal size of $82.5 \mathrm{~mm}$ carapace length). Each black dot represents a single observation. 
A

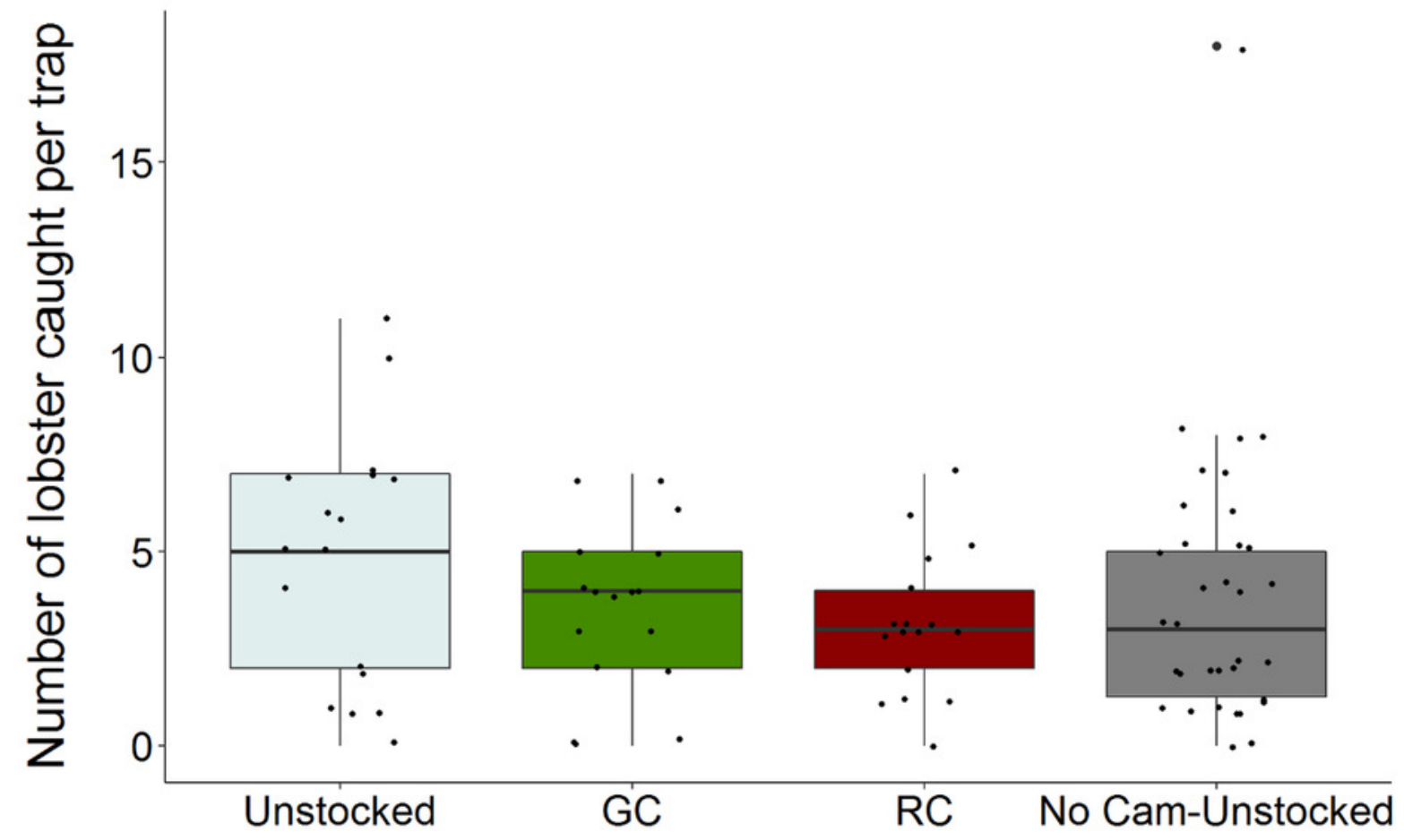

B

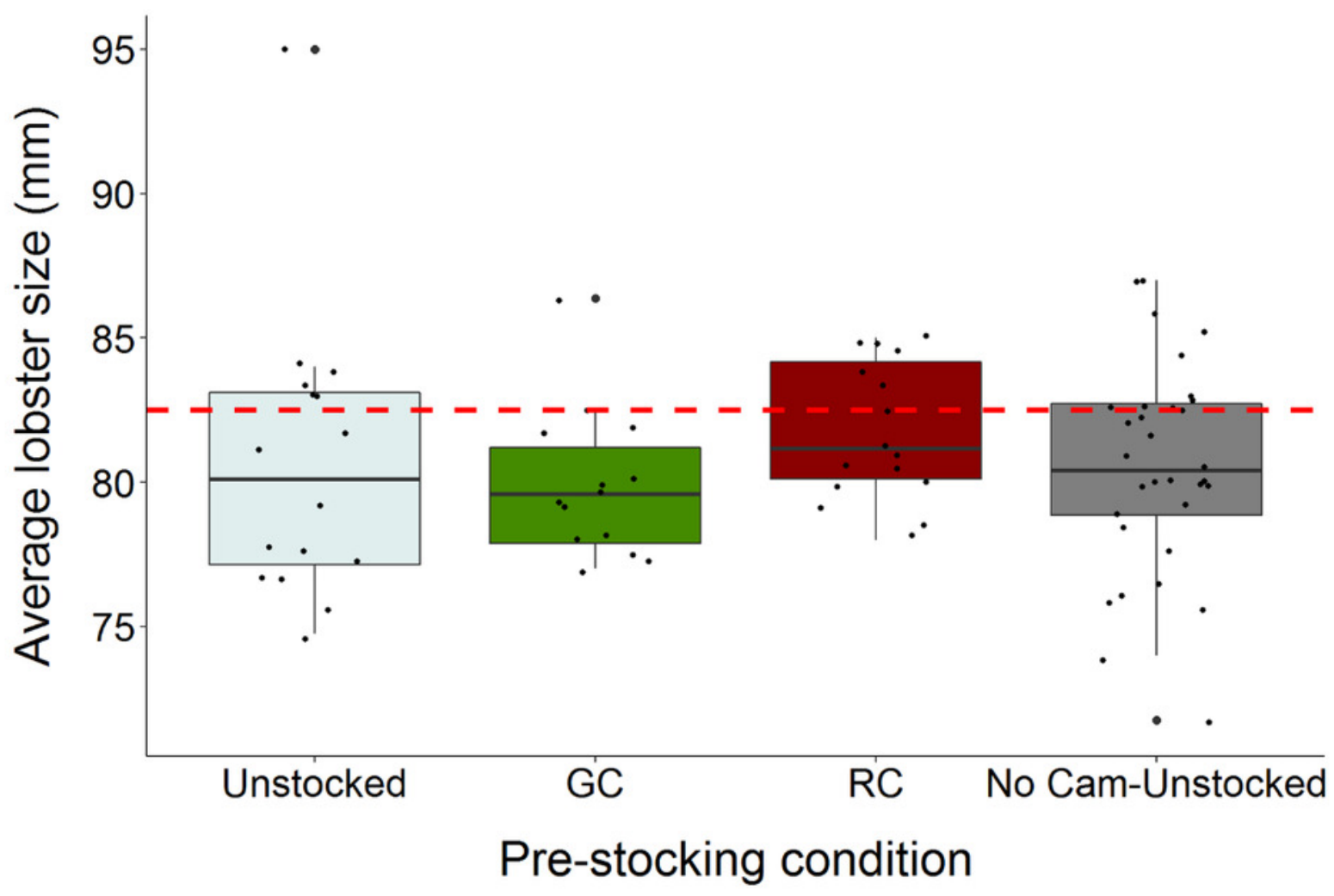


Figure 4

Video data analysis of lobster accumulation over the elapsed soak time for all entries and exits (ie. large and small-bodied lobster).

Each coloured line represents pre-stocking condition of traps. Numbers at the top right of each plot represents the deployment.

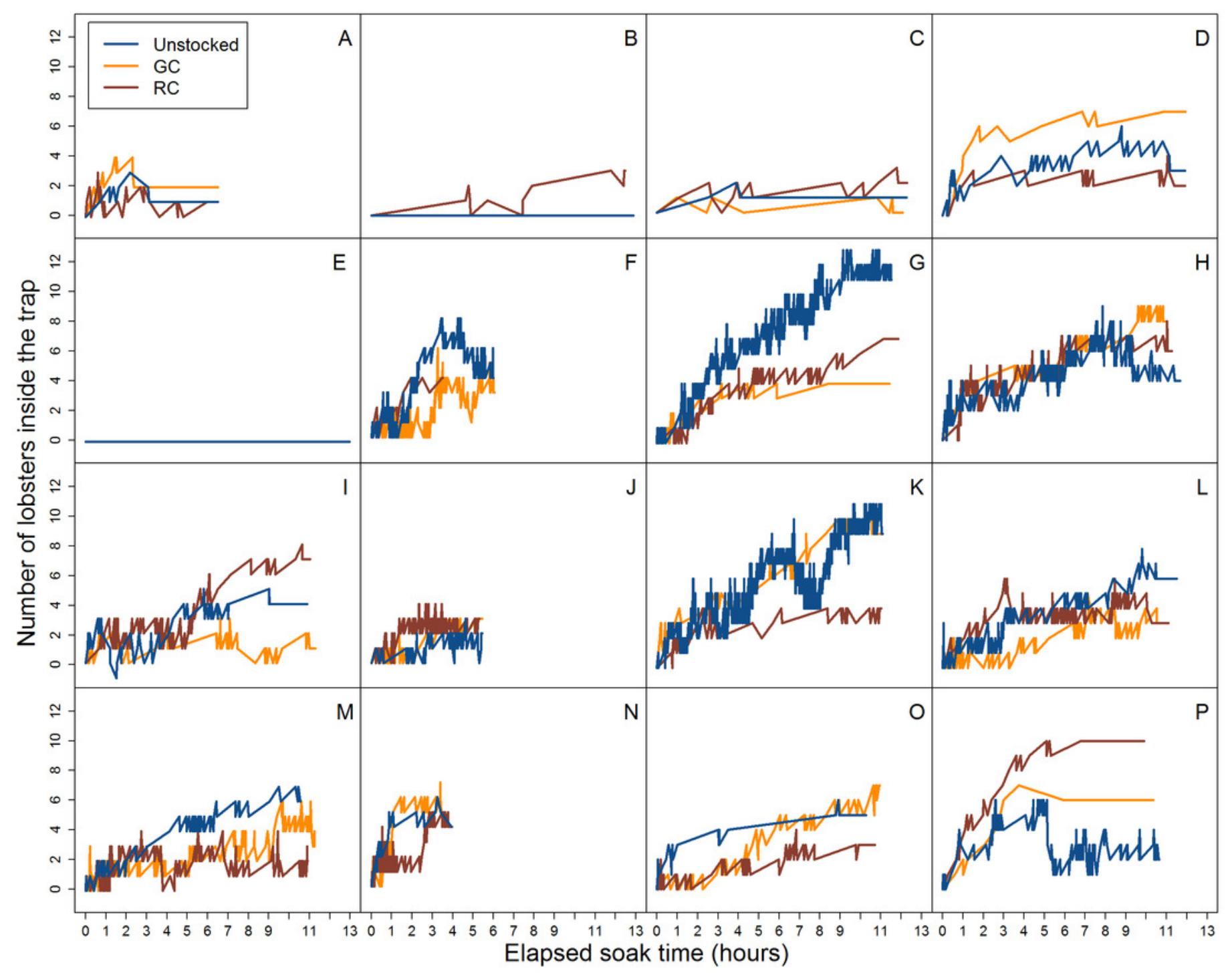


Figure 5

Video data analysis of lobster accumulation over the elapsed soak time for entries and exits through the trap entrance only (i.e. primarily large-bodied lobster).

Each coloured line represents trap pre-stocking condition. Numbers at the top right of each plot represents the deployment.

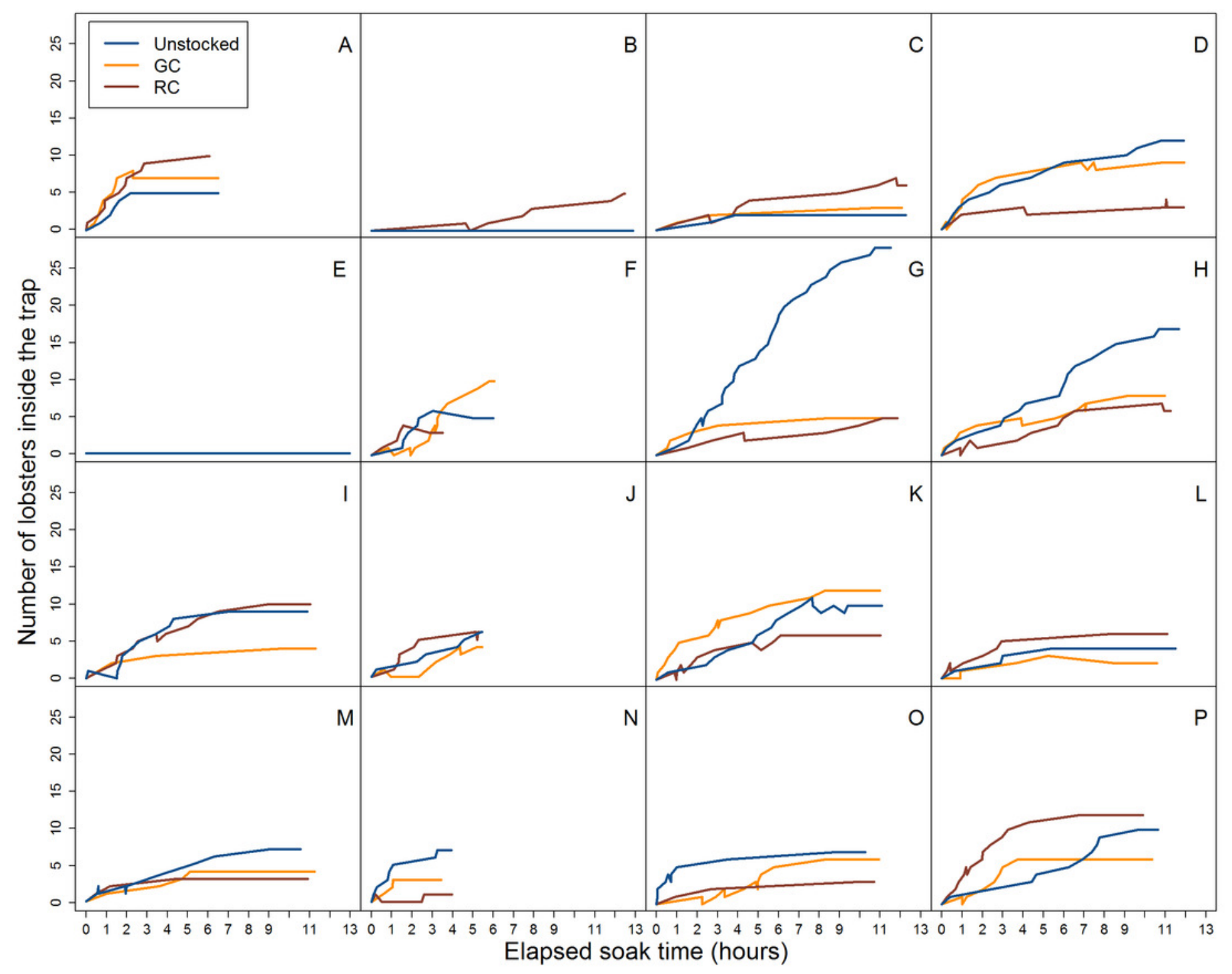




\section{Figure 6}

The proportion of lobster entry attempts that were either successful (blue) or failed (red) according to trap pre-stocking condition.

(A) all entry attempts. (B) entry attempts through the trap entrance only (i.e. primarily largebodied lobster). (C) entry attempts through the wire cells or escape slats only (i.e. primarily small-bodied lobsters).
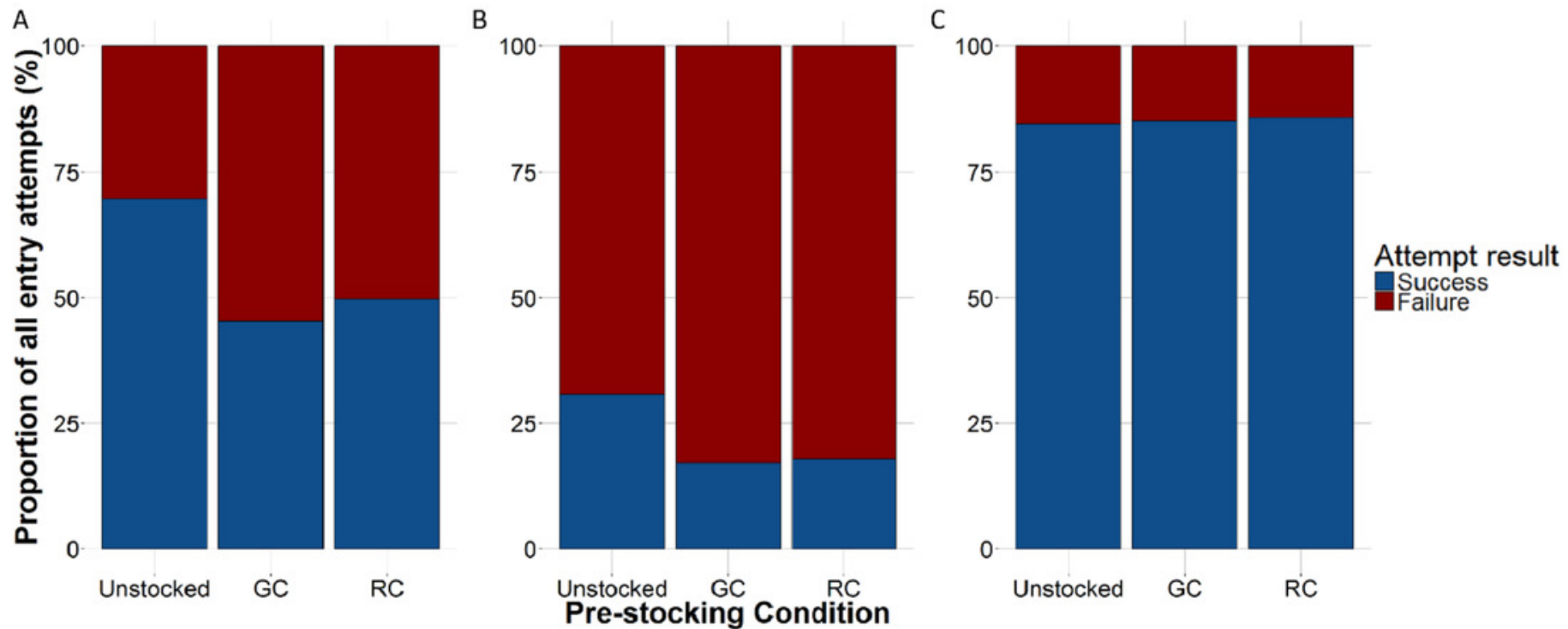


\section{Figure 7}

Total number of lobster entry events across trap pre-stocking condition for deployments with both video and SCUBA data $(\mathrm{N}=11)$.

Event outcomes include entry failure (red); entry succeeded, but lobster exited (blue); entry succeeded, lobster remains in the trap (grey). The black points and lines indicate mean ambient lobster density \pm 1 SD surveyed around each trap pre-stocking condition. The green triangles and lines indicate mean ambient green crab density \pm 1 SD surveyed around each trap pre-stocking condition $\mathrm{m} 2$

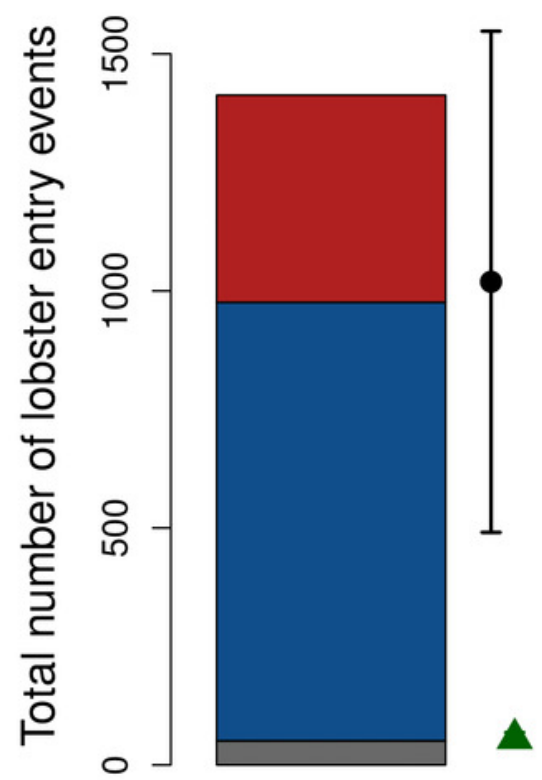

Unstocked

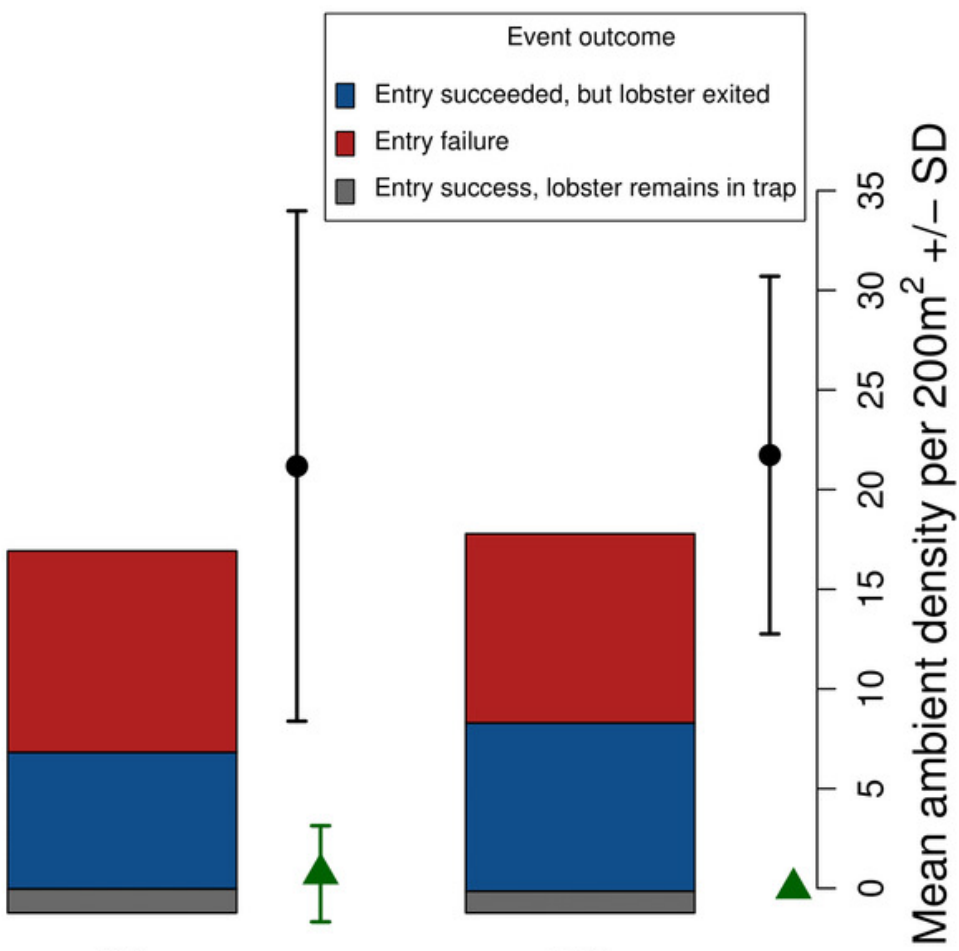

$\mathrm{RC}$

Pre-stocking condition 


\section{Table $\mathbf{1}$ (on next page)}

Model output from equation 1. Estimated regression parameters, standard errors, zvalues and P-values. 


\begin{tabular}{lllll} 
& Estimate & Std. error & $\mathrm{Z}$ value & P-value \\
\hline Intercept & 1.4476 & 0.1770 & 8.181 & $2.82 \mathrm{e}-16$ \\
$\begin{array}{l}\text { Green crab pre- } \\
\text { stock }\end{array}$ & -0.3124 & 0.1684 & -1.855 & 0.0636 \\
Rock crab pre-stock & -0.4364 & 0.1747 & -2.499 & 0.0125 \\
Unstocked trap & -0.2247 & 0.1396 & -1.610 & 0.1074
\end{tabular}




\section{Table 2 (on next page)}

Model output from equation 2. Estimated regression parameters, standard errors, zvalues and P-values. 


\begin{tabular}{lllll} 
& Estimate & Std. error & z value & P-value \\
\hline Intercept & 1.4447 & 0.1916 & 7.541 & $4.66 \mathrm{e}-14$ \\
Green crab pre-stock & -0.2908 & 0.2064 & -1.409 & 0.1589 \\
Rock crab pre-stock & -0.4155 & 0.2118 & -1.962 & 0.0498 \\
Unstocked trap & -0.2278 & 0.1735 & -1.313 & 0.1891
\end{tabular}

1 


\section{Table 3(on next page)}

Model output from equation 3. Estimated regression parameters, standard errors, zvalues and P-values. 


\begin{tabular}{lllll} 
& Estimate & Std. error & z value & P-value \\
\hline Intercept & 1.105111 & 0.189895 & 5.820 & $5.9 \mathrm{e}-09$ \\
Ambient Lobster & 0.016014 & 0.007093 & 2.258 & 0.024
\end{tabular}

1 